\title{
PENGARUH NOISE-MODULATED MONAURAL BEATS AUDITORY TERHADAP PENINGKATAN KAPASITAS MEMORI PADA LANSIA
}

\author{
THE EFFECTS OF NOISE-MODULATED MONAURAL BEATS AUDITORY \\ TOWARD MEMORY CAPACITY INCREMENT OF ELDERLY PATIENTS
}

\author{
Adre Mayza, ${ }^{*}$ Shella, ${ }^{* *}$ Brian Manurung**
}

\begin{abstract}
Introduction: Memory impairment is one of the disturbances of cognitive function that is often found and influential in elderly life activities. Memory impairment in elderly can be improved by applying several intervention modes, including auditory stimuli, because brain waves play a role in decreasing memory function in the elderly.

Aims: To determine the effect of noise-modulated monaural beats auditory stimulation on improves memory capacity in the elderly.

Methods: This study was a quasi-experiment with pre-test-post-test control group design, combining two methods of interventions; pink noise and monaural beats on alpha waves. Memory Impairment Screen (MIS) instrument were used to measure memory capacity. Subjects in this study came from the elderly population at the PELKRIS Foundation Semarang which has memory impairment based on MIS score $\leq 4$.

Results: There were 34 subjects of 75-90 years old with memory impairment. Most of them were women. There was significant positive effect of noise-modulated monaural beats auditory stimulation that improved memory capacity in $(p<0.001)$ and signifiant difference of influence between treatment group and control group $(p<0.001)$.

Discussion: There were positive and significant effect of noise-modulated monaural beats auditory stimulation to improves memory capacity in elderly.
\end{abstract}

Keywords: Elderly, memory, Memory Impairment Screen, monaural beats, noise stimulation

\section{ABSTRAK}

Pendahuluan: Gangguan memori merupakan salah satu masalah gangguan fungsi kognitif yang sering dihadapi para lansia dan berpengaruh dalam aktivitas kehidupan lansia. Masalah gangguan memori pada lansia dapat diatasi dengan beberapa metode intervensi, antara lain pemberian stimulus suara, karena gelombang otak berperan terhadap penurunan fungsi memori pada lansia.

Tujuan: Mengetahui pengaruh stimulus noise-modulated monaural beats auditory terhadap peningkatan kapasitas memori pada lansia.

Metode: Desain penelitian berupa kuasi eksperimen dengan teknik metode pre-test post-test control group design menggabungkan dua metode intervensi, yaitu penggabungan pink noise dan monaural beats pada gelombang alfa. Kapasitas memori diukur menggunakan instrumen Memory Impairment Screen (MIS). Subjek penelitian adalah populasi lansia di Yayasan PELKRIS, Semarang, yang mengalami gangguan memori berdasarkan skor MIS $\leq 4$.

Hasil: Didapatkan 34 subjek dengan penurunan fungsi memori yang usia terbanyak sekitar 75-90 tahun dan jumlah perempuan lebih banyak dibanding laki-laki. Terdapat pengaruh positif stimulus noise-modulated monaural beats auditory terhadap peningkatan kapasitas memori pada lansia yang signifikan $(\mathrm{p}<0,001)$ dan beda pengaruh antara kelompok perlakuan dan kelompok kontrol secara bermakna $(\mathrm{p}<0,001)$.

Diskusi: Terdapat pengaruh positif dan signifikan stimulus noise-modulated monaural beats auditory terhadap peningkatan kapasitas memori pada lansia.

Kata kunci: Lansia, memori, Memory Impairment Screen, monaural beats, stimulus noise

*Departemen Neurologi FK Universitas Indonesia/RSUPN Dr. Cipto Mangunkusumo, Jakarta; **Departemen Bioteknologi \& Neurosains Universitas Surya, Tangerang. Korespondensi: dr.adremayza05@gmail.com.

\section{PENDAHULUAN}

Undang-undang Republik Indonesia Nomor 13 tahun 1998 tentang kesejahteraan sosial lanjut usia menyatakan bahwa lanjut usia (lansia) adalah seseorang yang telah mencapai usia lebih dari 60 tahun. ${ }^{1}$ Salah satu masalah kesehatan pada lansia adalah penurunan fungsi kognitif, yaitu memori. Hal ini disebabkan oleh penurunan jumlah lapisan mielin pada usia lanjut yang berperan penting dalam mempertahankan fungsi kognitif. Lapisan tersebut meningkatkan integrasi informasi melalui jaringan saraf yang terdistribusi secara spasial untuk 
mendukung fungsi kognitif dan motorik. ${ }^{2}$

Gelombang otak memiliki peran terhadap penurunan fungsi memori pada lansia. Penelitian menunjukan bahwa gelombang alfa dan teta memiliki peranan dalam proses memori di otak. Gelombang otak alfa bekerja pada proses memori semantik, sedangkan gelombang teta bekerja pada proses memori episodik. ${ }^{3}$

Masalah gangguan memori pada lansia dapat diatasi dengan beberapa metode intervensi, antara lain pemberian stimulus suara. ${ }^{4}$ Stimulus suara (auditory beats) dibagi menjadi dua, yaitu monaural dan binaural beats. Kedua stimulus ini dihasilkan ketika frekuensi gelombang sinus yang berdekatan dengan amplitudo stabil didengarkan ke kedua telinga secara bersamaan (monaural) atau secara terpisah (binaural). ${ }^{5}$ Frekuensi binaural beats yang sesuai dengan aktivitas gelombang otak alfa memiliki efek positif pada kapasitas memori kerja. ${ }^{6-7}$

Penelitian Klimeschet dkk menunjukkan bahwa gelombang alfa dan teta berperan dalam proses memori di otak. ${ }^{6}$ Gelombang teta mengkodekan memori episodik sementara ke memori jangka panjang, sedangkan gelombang alfa mengkodekan memori semantik sementara ke memori jangka panjang. Metode intervensi peningkatan kapasitas memori lainnya adalah dengan memberikan stimulus noise. Noise dibedakan menjadi tiga macam berdasarkan perbedaan frekuensi spektrum gelombang suara dan kerapatan daya spektral, yaitu white, pink, dan brown noise. ${ }^{8}$

Peningkatan jumlah lansia yang juga berisiko mengalami gangguan memori akan menghambat kelangsungan hidup lansia menjadi tidak produktif. Minimnya penelitian di nasional maupun internasional untuk menangani penurunan kapasitas memori pada lansia menjadi alasan penelitian ini. Adapun metode yang paling efektif adalah menggabungkan kedua teknik intervensi monaural beats dan pink noise.

Peneliti menggunakan pink noise dikarenakan pink noise memiliki karakteristik suara yg lebih tenang dan lebih nyaman didengarkan di bandingkan dengan white atau brown noise. ${ }^{8}$ Selain itu penggunaan pink noise pada lansia yg sedang tidur dapat meningkatkan kemampuan memori 3 kali lebih besar dari sebelum pemberian stimulus dan memiliki hasil yg lebih efektif dibandingkan white noise. ${ }^{9}$

\section{TUJUAN}

Untuk mengetahui pengaruh stimulus noisemodulated monaural beats terhadap peningkatan kapasitas memori pada lansia.

\section{METODE}

Penelitian ini menggunakan desain eksperimental kuasi, yaitu data diambil sebelum dan sesudah pemberian perlakuan. Penelitian dilakukan terhadap para lansia (berusia $\geq 60$ tahun) di Yayasan PELKRIS, Semarang, pada bulan Mei hingga Juni 2018. Kapasitas memori diukur menggunakan instrumen Memory Impairment Screen (MIS) yang merupakan alat ukur kapasitas memori pada lansia (Gambar 1). Skor maksimal pada pemeriksaan ini adalah 8 dengan kriteria skor (5-8) tidak ada gangguan kognitif dan skor $\leq 4$ kemungkinan ada gangguan memori. ${ }^{10}$

Kriteria inklusi adalah subjek dengan nilai MIS $\leq 4$, sedangkan kriteria eksklusi adalah memiliki gangguan pendengaran, tidak dapat membaca, memiliki riwayat penyakit neurologi, dan memiliki riwayat penyakit epilepsi. Akibat keterbatasan subjek yang ada di lapangan yang sesuai dengan kriteria, maka penelitian ini tidak dapat membandingkan subjek berdasarkan tingkat pendidikan dan baseline data yang lainnya.

Subjek dilakukan tes pendengaran menggunakan suara dengan frekuensi $8000 \mathrm{~Hz}$ dan uji kapasitas memori berdasarkan MIS. Kemudian subjek dibagi ke dalam 2 kelompok, yaitu kelompok kontrol dan kelompok perlakuan. Kelompok perlakuan diberikan stimulus pink noise-modulated monaural beats auditory satu kali selama 15 menit, sedangkan kelompok kontrol tidak diberi perlakuan. Stimulus pink noise dibuat dengan amplitudo 0,2 Arbitrary Unit. Stimulus monaural beats dibuat dengan kombinasi frekuensi $400 \mathrm{~Hz}$ dan $410 \mathrm{~Hz}$ yang memiliki amplitudo 0,25 Arbitrary Unit dan menghasilkan frekuensi pada gelombang alfa $(10 \mathrm{~Hz})$ dengan amplitudo total sebesar 0,5 Arbitrary Unit.

Stimulus auditory dibuat menggunakan program Audacity 2.1.3. Program ini merupakan editor audio dan perekam multitrack gratis yang mudah 


\section{Intruksi Penggunaan}

1. Perlihatkan kepada pasien selembar kertas yang berisi 4 kata yang dicetak dalam huruf besar atau ukuran font 24 . Minta pasien untuk mengucapkan 4 kata tersebut dengan suara keras.

2. Katakan pada pasien bahwa tiap kata termasuk dalam suatu kategori. Berikan petunjuk di tiap kategori. Mintalah pasien untuk menunjukan kata mana yang termasuk dalam kategori yang disebutkan (contoh: "sebutkan kata mana yang termasuk dalam kategori permainan?”) Berikan kesempatan hingga 5 kali. Kegagalan dalam menyelesaikan tugas ini menunjukkan kemungkinan gangguan kognitif.

3. Saat pasien mampu mengidentifikasi 4 kata, ambil kertas yang berisi kata-kata. Minta pasien untuk mengingat 4 kata tersebut dalam beberapa menit.

4. Ajak pasien untuk mengikuti permainan pengalihan perhatian selama 2-3 menit. Seperti menghitung angka sampai 20, menghitung mundur dari angka 100 sebanyak 7x, mengeja mundur suatu kata, dan sebagainya.

5. FREE RECALL -2 poin per kata: Minta pasien untuk mengucapkan 4 kata yang sudah mereka ingat sebelumnya. Berikan waktu 5 detik untuk masing-masing kata. Bila dalam waktu 10 detik pasien tidak dapat mengingat kembali, lanjutkan ke tahap 6.

6. CUED RECALL -1 poin per kata: Bacakan petunjuk kategori yang sesuai pada kata yang tidak bisa diingat pasien pada tahap Free Recall (contoh: "kata mana yang masuk ke dalam kategori permainan?”).

\begin{tabular}{|l|l|l|l|}
\hline \multicolumn{1}{|c|}{ Kata } & \multicolumn{1}{|c|}{ Kategori } & Free recall (2 poin) & Cued recall (1 poin) \\
\hline Catur & Permainan & & \\
\hline Tempat saus & Hidangan & & \\
\hline Telegram & Pesan & & \\
\hline Red cross & Organisasi & & \\
\hline \multicolumn{2}{|c|}{ Skoring } \\
\hline
\end{tabular}

Gambar 1. Skrining Gangguan Memori (Memory Impairment Screen) ${ }^{11}$

digunakan untuk Windows, Mac OS X, GNU/Linux, dan sistem operasi lainnya. Stimulus suara disimpan dalam bentuk file MP3 dan diberikan selama 15 menit menggunakan headphone pada tingkat suara $60 \mathrm{~dB}$ yang diukur menggunakan sound level meter (alat ukur kebisingan suara). Pemberian stimulus hanya diberikan satu kali pada setiap subjek untuk melihat efek langsung dari stimulus terhadap memori pada lansia.

Penelitian ini mendapat persetujuan dari Komite Etik Penelitian Kesehatan (KPEK) FK Universitas Diponegoro Semarang, No. 186/EC/FKRSDK/IV/2018. Analisis statistik data menggunakan software SPSS 22 dengan menggunakan tingkat error $10 \%$ atau dengan nilai kemaknaan $\mathrm{p}<0,1$. Batas nilai kemaknaan tersebut digunakan karena jumlah subjek yang relatif kecil, sehingga kemungkinan nilai kesalahan lebih besar dibandingkan dengan sampel dalam jumlah besar. Dilakukan uji Wilcoxon untuk mengetahui pengaruh variabel bebas dengan variabel terikat, dan uji Mann-Whitney U untuk mengetahui perbedaan pengaruh stimulus antara kelompok perilaku dengan kelompok kontrol.

\section{HASIL}

Total populasi penelitian ini adalah 99 orang, namun hanya 34 subjek yang memenuhi kriteria inklusi yang dibagi menjadi masing-masing 17 subjek pada kelompok kontrol dan perilaku. Sebagian besar subjek penelitian pada kelompok perlakuan (70,6\%) dan kelompok kontrol (76,5\%) berusia 75-90 tahun (Tabel 1) dengan rerata usia pada rentang usia subjek terbanyak (75-90 tahun), yaitu 82,5 tahun.

Proporsi perempuan lansia lebih banyak memiliki gangguan memori, baik di kelompok perlakuan $(88,2 \%)$ dan kelompok kontrol $(82,4 \%)$. Lansia dengan gangguan memori memiliki riwayat penyakit antara lain hipertensi dan diabetes. Subjek pada penelitian ini sebelum mendapat perlakuan memiliki gangguan kongnitif yang dibuktikan dengan hasil MIS <4 (Tabel 2).

Uji normalitas dengan analisis uji One-Sample Shapiro-Wilk didapatkan bahwa data terdistribusi 
Tabel 1. Distribusi Subjek Berdasarkan Jenis Kelamin dan Usia $(n=34)$

\begin{tabular}{lcc}
\hline \multicolumn{1}{c}{ Karakteristik } & Kelompok Perlakuan $(\mathbf{n = 1 7})$ & Kelompok Kontrol $(\mathbf{n = 1 7})$ \\
\hline Jenis Kelamin & & \\
- Laki-laki & $2(11,8 \%)$ & $3(17,6 \%)$ \\
- Perempuan & $15(88,2 \%)$ & $14(82,4 \%)$ \\
Usia & & \\
- $60-74$ tahun & $3(17,6 \%)$ & $3(17,6 \%)$ \\
- $75-90$ tahun & $12(70,6 \%)$ & $13(76,5 \%)$ \\
- $>90$ tahun & $2(11,8 \%)$ & $1(5,9 \%)$ \\
\hline
\end{tabular}

Tabel 2. Hasil Pengukuran Kapasitas Memori pada Kedua Kelompok $(n=34)$

\begin{tabular}{|c|c|c|c|c|c|}
\hline \multirow{2}{*}{ Pemeriksaan } & \multirow{2}{*}{$\mathbf{n}$} & \multicolumn{2}{|c|}{ Nilai Kapasitas Memori } & \multirow{2}{*}{ Selisih } & \multirow{2}{*}{$\operatorname{Rerata} \pm$ SD } \\
\hline & & Minimum & Maksimum & & \\
\hline \multicolumn{6}{|c|}{ Kelompok Perlakuan } \\
\hline - Pre-test & 17 & 0 & 4 & 4 & $2,29 \pm 1,31$ \\
\hline - Post-test & 17 & 4 & 8 & 4 & $5,82 \pm 1,46$ \\
\hline \multicolumn{6}{|l|}{ Kelompok Kontrol } \\
\hline Pre-test & 17 & 0 & 4 & 4 & $2 \pm 1,54$ \\
\hline Post-test & 17 & 0 & 4 & 4 & $1,7 \pm 1,4$ \\
\hline
\end{tabular}

SD: standar deviasi.

tidak normal $(\mathrm{p}<0,1)$, yaitu nilai $\mathrm{p}$ pada kapasitas memori lansia pre- dan post-test di kelompok perlakuan adalah 0,07 dan 0,049 . Sementara nilai $\mathrm{p}$ pada kapasitas memori lansia pre dan post-test pada kelompok kontrol, yaitu 0,03 dan 0,045.

Uji homogenitas yang digunakan dalam penelitian ini adalah uji Levene, diperoleh nilai $\mathrm{p}$ pada pre-test kapasitas memori lansia pada setiap kelompok adalah 0,437 ( $>00,1)$, sehingga disimpulkan bahwa data awal setiap kelompok memiliki variasi yang homogen.

Berdasarkan hasil uji normalitas dan uji homogenitas, jenis data penelitian ini merupakan data ordinal, homogen dan distribusi tidak normal, sehingga dilakukan pengujian statistik menggunakan uji Wilcoxon dengan ketentuan bila $\mathrm{p}<0,1$ maka hipotesis diterima, dan berlaku sebaliknya (Tabel 3). Pada studi dengan uji statistik Wilcoxon ini, menunjukkan bahwa stimulus noise-modulated monaural beats auditory pada kelompok perlakuan memiliki pengaruh positif terhadap peningkatan Tabel 3. Hasil Uji Wilcoxon $(n=34)$

\begin{tabular}{lcc}
\hline \multicolumn{1}{c}{ Variabel } & p & Kesimpulan \\
\hline Kapasitas memori lansia di kelompok perlakuan & 0,000 & $\mathrm{H}_{1}$ diterima \\
Kapasitas memori lansia di kelompok kontrol & 0,102 & $\mathrm{H}_{1}$ ditolak \\
\hline
\end{tabular}

H1: hipotesis bahwa ada pengaruh positif peningkatan memori setelah pemberian stimulus noise-modulated monaural beats auditory pada lansia.

kapasitas memori lansia yang signifikan, yaitu dengan nilai $\mathrm{p}=0,000(\mathrm{p}<0,1)$. Berbeda dari kelompok perlakuan, hasil uji Wilcoxon pada kelompok kontrol menunjukan tidak ada pengaruh yang signifikan terhadap peningkatan kapasitas memori lansia dengan nilai $\mathrm{p}=0,102(\mathrm{p}<0,1)$.

Uji Mann-Withney U dilakukan untuk mengetahui perbedaan pengaruh stimulus noisemodulated monaural beats auditory terhadap peningkatan kapasitas memori lansia pada kelompok perlakuan dengan kelompok kontrol. Didapatkan hasil pada kelompok perlakuan $(25,76)$ lebih tinggi dari kelompok kontrol $(9,24)$, serta adanya perbedaan pengaruh yang signifikan antara kedua kelompok tersebut terhadap kapasitas memori pada lansia, dilihat berdasarkan nilai $p$ sebesar $0,000(p<0,1)$ (Tabel 4).

Berdasarkan kedua hasil uji Wilcoxon dan uji Mann-Whitney didapatkan hasil H1 (hipotesis 1) diterima, bahwa kedua uji menunjukkan hasil $p=0,000$ $(p<0,1)$ pada kelompok perlakuan. Pada kelompok 
Tabel 4. Hasil Uji Mann-Withney U (n=34)

\begin{tabular}{lccc}
\hline \multicolumn{1}{c}{ Variabel } & Rerata & p & Kesimpulan \\
\hline Kelompok perlakuan & 25,76 & 0,000 & $\mathrm{H}_{1}$ diterima \\
Kelompok kontrol & 9,24 & 0,000 & $\mathrm{H}_{1}$ diterima \\
\hline
\end{tabular}

H1: hipotesis bahwa ada pengaruh positif peningkatan memori setelah pemberian stimulus noise-modulated monaural beats auditory pada lansia.

perlakuan ditemukan peningkatan kapasitas memori berdasarkan peningkatan rerata post-test dari pretest. Sementara pada kelompok kontrol menunjukan tidak ada peningkatan kapasitas memori berupa nilai pre-test dan post-test memory impairment screen yang konstan (Tabel 2).

\section{PEMBAHASAN}

Penelitian ini mendapatkan banyaknya jumlah lansia perempuan dibandingkan laki-laki, sesuai dengan data statistik WHO bahwa angka harapan hidup pada perempuan lebih tinggi dibandingkan angka harapan hidup pada laki-laki. ${ }^{12}$ Gangguan memori lebih banyak ditemukan pada lansia perempuan ini mendukung pernyataan bahwa berkurangnya hormon estrogen pascamenopause pada perempuan memiliki peran dalam penurunan fungsi memori. ${ }^{13}$ Hormon estrogen diketahui memiliki peranan penting dalam pembentukan memori, sedangkan pada laki-laki, testosteron diubah menjadi estradiol oleh enzim aromatase yang terletak di sekeliling dan di seluruh otak laki-laki. Sekresi testis testosteron tidak pernah berhenti sama sekali sehingga kadar estrogen lebih tinggi pada laki-laki usia lanjut daripada pada perempuan pascamenopause. ${ }^{14}$

Lansia dengan rentang usia tersebut paling banyak mengalami penurunan kognitif, khususnya pada memori. ${ }^{15}$ Perlambatan terkait usia di cognitive processing speed (CPS) mendasari penurunan fungsi kognitif. ${ }^{11}$ Perlambatan ini terjadi setelah usia 30 tahun, yaitu proses mielinisasi mulai menurun dan mielin pada ujung saraf berkurang. Penurunan jumlah lapisan mielin pada usia lanjut menyebabkan munculnya gangguan fungsi kognitif. Disfungsi kolinergik, adanya endapan beta-amiloid, penyusutan hipokampal neurofibrillary atau peningkatan plak neuritis di korteks otak merupakan beberapa alasan yang menyebabkan koneksi memori pada otak dapat terhambat, sehingga menimbulkan penurunan fungsi memori dan peningkatan risiko penyakit gangguan memori, seperti demensia dan Alzheimer. ${ }^{11}$

Teori resonansi stokastik diketahui pemberian stimulus noise akan memperkuat dan mengoptimalkan impuls melalui proses remielinisasi. ${ }^{16}$ Pink noise membantu proses sinkronisasi gelombang otak (gelombang alfa) pada korteks auditori melalui proses remielinisasi yaitu terbentuknya kembali selubung mielin pada ujung saraf. ${ }^{16}$ Mielinisasi pada akson menghasilkan terjadinya potensial aksi yang meningkatkan kecepatan transmisi sinyal sehingga terbentuk pergerakan saraf yang menghasilkan gelombang saraf, salah satunya adalah gelombang alfa yang diperlukan dalam pembentukan memori.

Dilihat dari hasil antara nilai pre- dan posttest kapasitas memori pada kelompok kontrol, diperoleh hasil yang konstan dan hasil bernilai negatif yang menunjukan penurunan kapasitas memori. Disebutkan bahwa bila tidak ada pemberian stimulus pada otak yang dapat merangsang aktivasi saraf yang telah mati, maka fungsi otak akan mengalami kemunduran dan akan berdampak pada fungsi kognitif berupa gangguan pada memori yang progresif. ${ }^{17}$

Pemberian stimulus pendengaran dapat menghasilkan sinkronisasi gelombang otak yang dapat membantu proses pembentukan memori. ${ }^{18}$ Lansia yang diberi stimulus binaural beats satu kali selama 15 menit pada gelombang alfa dapat menghasilkan memori yang lebih baik dari pada sebelum pemberian stimulus. ${ }^{18}$ Hal ini sesuai dengan hasil penelitian ini, pada kelompok perlakuan terdapat peningkatan kapasitas memori, dengan adanya peningkatan nilai pre-test dan post-test memory impairment screen setelah pemberian stimulus suara. Penambahan pink noise ke dalam stimulus binaural beats bertujuan untuk meningkatkan dan mengoptimalkan respons saraf terhadap stimulus yang diberikan. Stimulus noise-modulated monaural beats auditory menghasilkan sinkronisasi gelombang otak alfa pada lansia yang diperlukan dalam pembentukan memori. Proses sinkronisasi gelombang otak alfa diperlukan, karena pada lansia terjadi peningkatan gelombang lambat (delta dan teta) yang menyebabkan terjadinya penurunan fungsi kognitif seperti memori. ${ }^{19}$ Harapan 
dari penelitian ini adalah mengurangi jumlah gelombang lambat dan meningkatkan gelombang aktif (beta dan alfa) untuk menghasilkan peningkatan fungsi kognitif.

\section{KESIMPULAN}

Stimulus noise-modulated monaural beats auditory memiliki pengaruh positif dan signifikan terhadap peningkatan kapasitas memori pada lansia.

\section{DAFTAR PUSTAKA}

1. Kementerian Kesehatan Republik Indonesia. Pusat Data dan Informasi Kementerian Kesehatan Republik Indonesia; 2015.

2. Williamson JM, Lyons DA. Myelin dynamics throughout life: An ever-changing landscape? Frontiers in cellular neuroscience [serial online]. 2018 [diunduh 25 Juni 2019]. Tersedia dari: Frontiers Media SA.

3. Klimesch W. EEG alpha and theta oscillations reflect cognitive and memory performance: A review and analysis. Brain Res Rev. 1999;29(2-3):169-95.

4. Oster G. Auditory beats in the brain. Sci Am. 1973;229(4):94-102.

5. Chaieb L, Wilpert EC, Reber TP, Fell J. Auditory beat stimulation and its effect on cognition and mood states. Frontiers in Cellular Neuroscience [serial online]. 2015 [diunduh 25 Juni 2019]. Tersedia dari: Frontiers Media SA.

6. Klimesch W, Schimke H, Schwaiger J. Episodic and semantic memory: An analysis in the EEG theta and alpha band. Electroencephalogr Clin Neurophysiol. 1994;91(6):428-41.

7. Kraus J, Porubanova M. The effect of binaural beats on working memory capacity. Stud Psychol (Bratisl). 2015;57(2):135-45.

8. Ahmed S, Afroz F, Tawsif A, Hug A. Cancellation of white and color noise with adaptive filter using LMS algorithm. IJWMN. 2015;7(4):19-36.

9. Zee PC, Santostasi G, Papalambros NA. Acoustic enhancement of sleep slow oscillations and concomitant memory improvement in older adults. Front Hum Neurosci. 2017.

10. Buschke H, Kuslansky G, Katz M, Stewart WF, Sliwinski MJ, Eckholdt HM, dkk. Screening for dementia with the Memory Impairment Screen. Neurology. 1994:52(2):231-8.

11. Lu PH, Lee GJ, Raven EP, Tingus $\mathrm{K}$, Khoo T, Thompson PM, dkk. Age-related slowing in cognitive processing speed is associated with myelin integrity in a very healthy elderly sample. J Clin Exp Neuropsychol. 2011;33(10):1059-68.

12. WHO. Life expectancy increased by 5 years since 2000, but health inequalities persist. Saudi Medical J [serial online]. 2016 [diunduh 29 Oktober 2015] Tersedia dari: WHO Newsroom.

13. Janicki SC, Schupf N. Hormonal influences on cognition and risk for Alzheimer's disease. Current Neurol Neurosci Reports. 2010;10(5):359-66.

14. Ali SA, Begum T, Reza F. Hormonal influences on cognitive function. Malays J Med Sci. 2018;25(4):3141.

15. Di-Carlo A, Baldereschi M, Amaducci L, Maggi S, Grigoletto F, Scarlato G, dkk. Cognitive impairment without dementia in older people: Prevalence, vascular risk factors, impact on disability. The Italian longitudinal study on aging. J Am Geriatr Soc. 2000;48(7):775-82.

16. Onorato I, D'Alessandro G, Di Castro MA, Renzi M, Dobrowolny G, Musaro A, dkk. Noise enhances action potential generation in mouse sensory neurons via stochastic resonance. PLoS One. 2016;11(8):e0160950.

17. Park DC, Bischof GN. The aging mind: Neuroplasticity in response to cognitive learning. Dialogues Clin Neurosci. 2013;15(1):109-19.

18. Ortiz T, Martinez AM, Fernandez A, Maestu F, Campo $\mathrm{P}$, Hornero R, dkk. Impact of auditory stimulation at a frequency of $5 \mathrm{~Hz}$ in verbal memory. Actas Esp Psiquiatr. 2008;36(6):307-13.

19. Hartman-Stein, Paula E, LaRue A, editor. Enhancing cognitive fitness in adults. New York: Springer; 2011. h. $433-40$. 